\title{
POTENSI PENGEMBANGAN AGROFORESTRI BERBASIS TUMBUHAN BUAH LOKAL
}

The Potential for Agroforestry Development Based on Local Fruit Plant

\author{
MINDA ARDINI*1 ${ }^{1}$, AKNES MARSELA ${ }^{2}$, RIRIN MUSTIKA $^{3}$, RIRIN SUBAKTI $^{4}$, SUCI $^{2}$ \\ KHAIRANI $^{5}$, ADI BEJO SUWARDI ${ }^{6}$ \\ 1,2,3,4,5,6 Program Studi Pendidikan Biologi, Fakultas Keguruan dan Ilmu Pendidikan, Universitas Samudra, \\ Jl. Meurandeh, Kota Langsa, Provinsi Aceh, Indonesia \\ Email: purbaminda950@gmail.com
}

\begin{abstract}
ABSTRAK
Agroforesi merupakan suatu system pengelolaan lahan yang dibuat untuk mengatasi masalah yang timbul akibat alih guna lahan untuk mengatasi masalah pangan. Agroforestri bertujuan agar sumber daya yang ada dapat dimanfaatkan secara optimal dan berkelanjutan. Beragamnya tumbuhan buah lokal yang tumbuh di Aceh Timur sangat berpotensi untuk meningkatkan perekonomian masyarakat Aceh Timur. Penelitian ini bertujuan untuk menganalisis potensi agroforestri tumbuhan buah-buahan local di kecamatan Birem Bayeun, kabupaten Aceh Timur, Indonesia. Penelitian ini dilakukan di 5 desa di Kecamatan Birem Bayeun, Kabupaten Aceh Timur yaitu desa Jamur Labu,desa Buket Seuleumak,desa Bukit Tiga, desa Blang Tualang dan desa Keude Birem. Penelitian dilakukan menggunakan metode observasi, survey, eksporasi, dan wawancara yang terstruktur melalui kuesioner. Sebanyak 125 orang responden yang tediri atas 25 orang per desa dipilih secara acak. Wawancara dilakukan dengan menggunakan kuesioner yang berisi persepsi masyarakat terhadap pengembangan buah lokal. Hasil penelitian telah menemukan sebanyak 30 jenis tumbuhan buah yang terdiri dari 20 famili dan 29 genus. Citrus sinensis merupakan jenis tumbuhan buah yang berpotensi dikembangkan di Kecamatan Birem Bayeun, Kabupaten Aceh Timur.
\end{abstract}

Kata Kunci : Agroforesti, buah lokal, ekonomi, Birem Bayeun

\begin{abstract}
Agroforesi is a land management system created to overcome problems arising from land use change to overcome food problems. Agroforestry aims to make available resources optimally and sustainably utilized. The diversity of local fruit plants that grow in East Aceh has the potential to improve the economy of the people of East Aceh. This study aims to analyze the potential of agroforestry of local fruit plants in the district of Birem Bayeun, East Aceh district, Indonesia. This research was conducted in 5 villages in Birem Bayeun Subdistrict, East Aceh Regency, namely Jamur Labu Village, Buket Seuleumak Village, Bukit Tiga Village, Blang Tualang Village and Keude Birem Village. The study was conducted using the method of observation, surveying, exportation, and structured interviews through questionnaires. A total of 125 respondents consisting of 25 people per village were chosen randomly. Interviews were conducted using a questionnaire that contained community perceptions of local fruit development. The results of the study had found as many as 30 types of fruit plants consisting of 20 families and 29 genera.
\end{abstract}

Keywords: Agroforestry, local fruit, economy, Birem Bayeun

Diterima : 17 Mei 2020. Disetujui: 24 Agustus 2020 


\section{PENDAHULUAN}

Agroforesi merupakan suatu system pengelolaan lahan yang ditawarkan untuk mengatasi masalah yang timbul akibat alih guna lahan untuk mengatasi masalah pangan, Bentuk agroforesti secara umum mencakup kebun campuran, tegalan berpohon, loading, lahan bera (belukar), kebun pekarangan, hutan tanaman rakyat yang lebih luas yang lebih kaya jenis (Hadi, 2013) di beberapa daerah terutama di pedesaan pengembangan pekarangan umumnya diarahkan untuk memenuhi sumber pangan sehari-hari, sehingga disebut sebagai lumbung hidup atau warung hidup (Rahayu dan Prawiroatmodjo, 2005). Menurut Suharjito et al. (2003) bahwa aspek penting yang sering dikaji dalam penerapan agroforestri diantaranya aspek teknis agronomis, silvikultur, aspek sosial ekonomi serta aspek ekologi. Aspek teknis agronomis dan silvikultur yaitu kajian kesesuaian kombinasi antara tanaman kehutanan dan tanaman pertanian untuk mendapatkan produktivitas yang lebih tinggi. Kajian aspek sosial ekonomi diantaranya mempelajari kombinasi jenis tanaman bagaimana yang dapat memberikan pendapatan yang menguntungkan bagi petani.

Maurapey, A (2013) mengungkapkan dalam pengelolaan dan pemanfaatan sumber daya lahan, akan timbul permasalahan jika kegiatan pembangunan dan hasil yang akan dicapai tidak sesuai dengan tujuan pengelolaan yang diharapkan. Adapun tujuan pengelolaan yang diharapkan adalah agar sumber daya yang ada dapat dimanfaatkan secara optimal dan berkelanjutan, dalam arti kesejahteraan masyarakat dapat meningkat tanpa menimbulkan terjadinya kerusakan dan degredasi sumber daya alam dan lingkungan yang dapat merugikan kelangsungan hidup generasi yang akan datang. Sistem agroforestri menekankan penggunaannya pada jenis-jenis pohon serba guna dan menentukan asosiasi antara jenis-jenis vegetasi yang ditanam. Dalam konteks agroforestri, pohon serbaguna mengandung pengertian semua pohon atau semak yang digunakan dan dikelola untuk lenih dari satu kegunaan produk atau jasa yang penekanannya pada aspek ekonomis dan ekologis (Senoaji, 2012). Penelitian ini bertujuan untuk menganalisis potensi agroforestri tumbuhan buah-buahan local di kecamatan Birem Bayeun, kabupaten Aceh Timur, Indonesia.

\section{METODE PENELITIAN}

\section{Lokasi dan Waktu Penelitian}

Penelitian ini dilkukan di 5 desa di kecamatan Birem Bayeun Kabupaten Aceh Timur yaitu Desa Jamur Labu, Desa Buket Seuleumak, Desa Buket Tiga, Desa Blang Tualang dan Desa Keude Birem (Gambar 1).

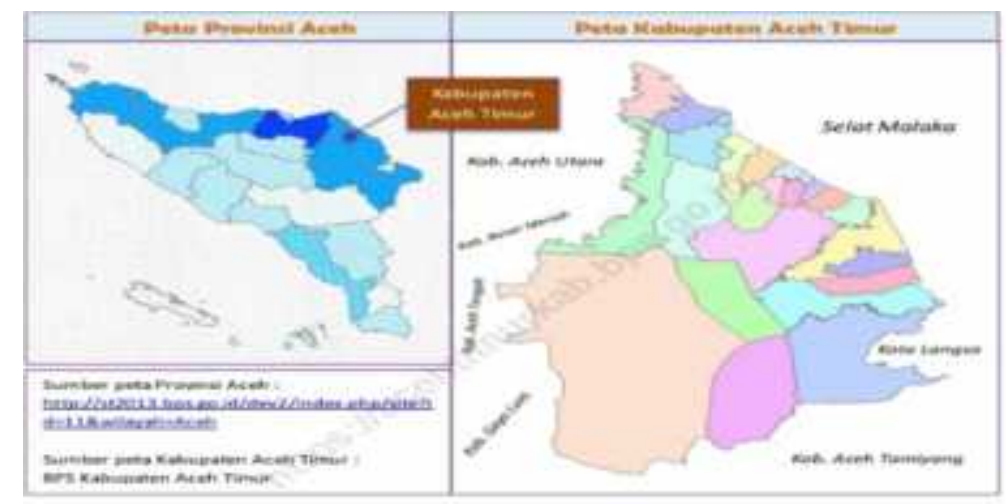


Gambar 1. Lokasi penelitian

\section{Metode Penelitian}

Penelitian ini dilakukan menggunakan metode observasi, survei, explorasi, dan wawancara yang terstuktur melalui kuesioner untuk mengetahui keragaman jenis tanaman dan jumlah individu jenis-jenis tanaman agroforestry di Desa Jamur Labu.

Penelitian dilakukan pada bulan Januari - Maret 2020 di kebun dan pekarangan rumah masyarakat. Semua tumbuhan buah yang ditemukan dicatat nama lokal, dikoleksi dan diidentifikasi di laboratorium Biologi Universitas Samudra.

Metode Rapid Rural Appraisal (RRA) digunakan untuk mengetahui persepsi masyarakat terhadap potensi pengembangan agroforestri berbasis tumbuhan buah. Sebanyak 125 orang responden yang tediri atas 25 orang per desa dipilih secara acak. Wawancara dilakukan dengan menggunakan kuesioner yang berisi persepsi masyarakat terhadap pengembangan buah lokal. Wawancara dilakukan dari orang per orang (face to face) dengan menggunakan bahasa Indonesia dengan rentang waktu antara 10-20 menit per responden. Preferensi responden terhadap jenis tanaman buah tertentu dinilai dengan menggunakan skoring 1-5 (1= sangat kurang baik, 2 = kurang baik, $3=$ cukup, $4=$ baik, 5 = sangat baik).

\section{HASIL DAN PEMBAHASAN}

\section{Keanekaragaman Jenis Tumbuhan Buah- Buahan}

Sebanyak 30 jenis tumbuhan buah lokal yang terdiri dari 20 famili dan 29 genus ditemukan di lokasi penelitian (Tabel 1).

Tabel 1. Jenis Tanaman Buah Lokal di Lokasi Penelitian

\begin{tabular}{|c|c|c|c|}
\hline Nama Jenis & Nama Lokal & Famili & Lokasi ditemukan \\
\hline Ananas comosus (L.) Merr. & Nanas & Bromeliaceae & $\begin{array}{l}\text { Keude Birem, Bukit Tiga } \\
\text { dan Blang Tualang }\end{array}$ \\
\hline Annona muricata $\mathrm{L}$. & Sirsak & Annonaceae & Jambur Labu, Blang Tualang \\
\hline Annona squamosa Linnaeus & Srikaya & Anonacecae & Bukit Tiga, Blang Tualang \\
\hline Artocarpus heterophyllus Lamk. & Nangka & Moraceae & $\begin{array}{l}\text { Buket Seuleumak, Blang } \\
\text { Tualang }\end{array}$ \\
\hline Averrhoa bilimbi L. & Belimbing Wuluh & Oxalidaceae & $\begin{array}{l}\text { Bukit Tiga, Blang Tualang, } \\
\text { Jambur labu,Buket } \\
\text { Seuleumak dan Keude } \\
\text { Birem }\end{array}$ \\
\hline Averrhoa carambola L. & Belimbing & Oxalidaceae & $\begin{array}{l}\text { Bukit Tiga, Blang Tualang, } \\
\text { Jambur labu,Buket } \\
\text { Seuleumak. }\end{array}$ \\
\hline Baccaurea motleyana Mull.Arg. & Rambai & Phyllanthaceae & $\begin{array}{l}\text { Keude Birem, Blang } \\
\text { Tualang }\end{array}$ \\
\hline Carica papaya $\mathrm{L}$. & Pepaya & Caricaceae & Bukit Tiga, Blang Tualang \\
\hline Citrus $\times$ aurantiifolia Swingle & Jeruk nipis & Rutaceae & Bukit Tiga, Blang Tualang \\
\hline $\begin{array}{l}\text { Citrullus lanatus (Thunb.) } \\
\text { Matsum. \& Nakai }\end{array}$ & Semangka & Cucurbitaceae & Jambur Labu,Keude Birem \\
\hline Citrus maxima Osbeck & Jeruk Bali & Rutaceae & $\begin{array}{l}\text { Blang tualang dan Bukit } \\
\text { Tiga }\end{array}$ \\
\hline Citrus sinensis Linnaeus & Jeruk manis & Rutaceae & $\begin{array}{l}\text { JamburLabu, Buket } \\
\text { Seuleumak, }\end{array}$ \\
\hline
\end{tabular}




\begin{tabular}{|c|c|c|c|}
\hline Citrus hystrix DC. & Jeruk purut & Rutaceae & $\begin{array}{l}\text { Keude Birem dan Jmabur } \\
\text { Labu }\end{array}$ \\
\hline Cocos nucifera L. & Kelapa & Arecaceae & $\begin{array}{l}\text { Jambur Labu, Blang tualang, } \\
\text { dan Buket Tiga }\end{array}$ \\
\hline Dimocarpus longan Lour. & Lengkeng & Sapindaceae & $\begin{array}{l}\text { Keude Birem, Blang } \\
\text { Tualang, Buket Seuleumak }\end{array}$ \\
\hline Durio zibethinus L. & Durian & Malvaceae & Jambur Labu,Bukit Tiga \\
\hline Garcinia mangostana $\mathrm{L}$. & Manggis & Clusiaceae & Jambur Labu,Bukit Tiga \\
\hline $\begin{array}{l}\text { Hylocereus costaricensis } \\
\text { Britton\&Rose }\end{array}$ & Buah naga & Cactaceae & Jambur Labu, Blang Tualang \\
\hline Manilkara zapota (L.) P.Royen & Sawo manila & Sapotaceae & $\begin{array}{l}\text { Keude Birem, Jambur Labu, } \\
\text { Buket Seuleumak }\end{array}$ \\
\hline Mangifera foetida Lour. & Bacang & Anacardiaceae & Keude Birem, Jambur Labu \\
\hline Mangifera odorata Griffith & Kuweni & Anacardiaceae & $\begin{array}{l}\text { Bukit Tiga, Blang Tualang, } \\
\text { Jambur labu,Buket } \\
\text { Seuleumak }\end{array}$ \\
\hline Morinda citrifolia $\mathrm{L}$. & Mengkudu & Rubiaceae & $\begin{array}{l}\text { Blang Tualang, Jambur } \\
\text { Labu,Bukit Tiga, Keude } \\
\text { Birem }\end{array}$ \\
\hline Musa acuminate Linnaeus & Pisang & Musaceae & $\begin{array}{l}\text { Blang Tualang, Jambur } \\
\text { Labu, Buket Tiga dan Keude } \\
\text { Birem }\end{array}$ \\
\hline Nephelium lappaceum L. & Rambutan & Sapindaceae & $\begin{array}{l}\text { Bukit Tiga, Blang Tualang, } \\
\text { Jambur labu,Buket } \\
\text { Seuleumak }\end{array}$ \\
\hline Psidium guajava $\mathrm{L}$. & Jambu biji & Myrtoideae & $\begin{array}{l}\text { Blang Tualang, Jambur } \\
\text { Labu,dan Bukit Tiga }\end{array}$ \\
\hline Salacca zalacca (Gaertn.) Voss & Salak & Arecaceae & $\begin{array}{l}\text { Blang tualang dan Buket } \\
\text { Tiga }\end{array}$ \\
\hline Spondias dulcis L. & Kedongdong & Anacardiaceae & Bukit Tiga, Jambur Labu \\
\hline $\begin{array}{l}\text { Syzygium malaccense (L.) Merr. } \\
\text { \&Perry }\end{array}$ & Jambu Bol & Myrtaceae & $\begin{array}{l}\text { Buket Seuleumak, Jambur } \\
\text { Labu, dan Blang Tualang }\end{array}$ \\
\hline Tamarindus indica $\mathrm{L}$. & Asam jawa & Fabaceae & $\begin{array}{l}\text { Jambur Labu, Buket } \\
\text { Seuleumak, dan Blang } \\
\text { Tualang }\end{array}$ \\
\hline Theobroma cacao L. & Kakao & Malvaceae & Jambur Labu,Keude Birem \\
\hline
\end{tabular}

jenis tumbuhan ini lebih banyak ditanam

Pada penilitian tumbuhan agroforestri dipekarangan rumah.

tersebut famili Rutaceae merupakan jenis tumbuhan buah yang paling banyak ditemui disetiap perkebunan karena tidak sulit untuk dirawat, rasa buah yang sedap dan mudah tumbuh didaerah dataran tinggi dan rendah membuat petani tidak takut menanaman \pm 1000 batang pohon hingga menghasilkan jumlah panen buah yang sangat berlimpah mulai dari $700 \mathrm{~kg}$ s/d $1000 \mathrm{~kg}$. Sedangkan famili Rubiaceae merupakan jenis famili yang paling sedikit ditemui hal disebabkan karena

\section{Nilai Ekonomi Tumbuhan Buah Lokal}

Survei pasar menunjukkan bahwa banyak tumbuhan buah lokal yang dijual di pasar tradisional dan memiliki potensi untuk Survei pasar menunjukkan bahwa banyak tumbuhan buah lokal yang dijual di pasar tradisional dan memiliki potensi untuk meningkatkan pendapatanmasyarakat setempat (Tabel 2). 
Tabel 2. Nilai Ekonomi Tumbuhan Buah Lokal

\begin{tabular}{|c|c|c|c|c|}
\hline Nama Jenis & $\begin{array}{c}\text { Bagian } \\
\text { Tumbuhan }\end{array}$ & Rata-Rata Panen & $\begin{array}{r}\text { Harga J } \\
(\mathbf{R p}) \\
\end{array}$ & \\
\hline Ananas comosus & Buah & $7000 \quad \mathrm{Kg}$ & 5.000 & $/ \mathrm{kg}$ \\
\hline Annona muricata & Buah & $60 \mathrm{Kg}$ & 15.000 & $/ \mathrm{kg}$ \\
\hline Annona squamosa & Buah & $100 \mathrm{Kg}$ & 30.000 & $/ \mathrm{kg}$ \\
\hline Artocarpus heterophyllus & Buah & 500 Buah & 3.000 & /buah \\
\hline Averrhoa carambola & Buah & $20 \mathrm{Kg}$ & 15.000 & / kg \\
\hline Averrhoa bilimbi & Buah & $30 \mathrm{Kg}$ & 10.000 & $/ \mathrm{kg}$ \\
\hline Baccaurea motleyana & Buah & $100 \mathrm{Kg}$ & 4.000 & $/ \mathrm{kg}$ \\
\hline Carica papaya & Buah & 500 Buah & 4.000 & /buah \\
\hline Citrus hystrix & Buah & $50 \quad \mathrm{Kg}$ & 15.000 & $/ \mathrm{kg}$ \\
\hline Citrullus lanatus & Buah & $1000 \mathrm{Kg}$ & 2.500 & $/ \mathrm{kg}$ \\
\hline Citrus maxima & Buah & $150 \quad \mathrm{Kg}$ & 12.000 & $/ \mathrm{kg}$ \\
\hline Citrus sinensis & buah & $7000 \mathrm{~kg}$ & 5.000 & $/ \mathrm{kg}$ \\
\hline Citrus $\times$ aurantiifolia & Buah & $50 \quad \mathrm{Kg}$ & 13.000 & $/ \mathrm{kg}$ \\
\hline Cocos nucifera & Buah & 2400 Buah & 1.600 & $/ \mathrm{kg}$ \\
\hline Dimocarpus longan & Buah & $200 \mathrm{Kg}$ & 30.000 & $/ \mathrm{kg}$ \\
\hline Durio zibethinus & Buah & 1000 Buah & 15.000 & /buah \\
\hline Garcinia mangostana & Buah & $450 \quad \mathrm{Kg}$ & 15.000 & $/ \mathrm{kg}$ \\
\hline Hylocereus costaricensis & Buah & $300 \mathrm{Kg}$ & 10.000 & $/ \mathrm{kg}$ \\
\hline Manilkara zapota & Buah & $500 \quad \mathrm{Kg}$ & 2.000 & $/ \mathrm{kg}$ \\
\hline Mangifera foetida & Buah & $75 \quad \mathrm{Kg}$ & 15.000 & $/ \mathrm{kg}$ \\
\hline Mangifera odorata & Buah & $70 \mathrm{Kg}$ & 12.000 & $/ \mathrm{kg}$ \\
\hline Morinda citrifolia & Buah & $500 \quad \mathrm{Kg}$ & 15.000 & $/ \mathrm{kg}$ \\
\hline Musa acuminata & Buah & 800 buah & 25.000 & /buah \\
\hline Nephelium lappaceum & Buah & $500 \quad \mathrm{Kg}$ & 7.000 & $/ \mathrm{kg}$ \\
\hline Psidium guajava & Buah & $300 \quad \mathrm{Kg}$ & 15.000 & / buah \\
\hline Salacca zalacca & Buah & $700 \quad \mathrm{Kg}$ & 15.000 & $/ \mathrm{kg}$ \\
\hline Spondias dulcis & Buah & $300 \quad \mathrm{Kg}$ & 12.000 & $/ \mathrm{kg}$ \\
\hline Syzygium malaccense & Buah & $50 \mathrm{Kg}$ & 20.000 & $/ \mathrm{kg}$ \\
\hline Tebroma cacao & Buah & $7000 \quad \mathrm{Kg}$ & 5.000 & $/ \mathrm{kg}$ \\
\hline
\end{tabular}

Hasil penelitian menunjukkan $72 \%$ responden telah menjual tumbuhan buah untuk meningkatkan pendapatan rumah tangga. Tumbuhan buah lokal yang memiliki nilai ekonomi tinggi antara lain Annona squamosa Linnaeus. Dimocarpus longan Lour. Musa acuminate Linnaeus dan Syzygium malaccense (L.) Merr. Kontribusi tumbuhan buah terhadap total pendapatan rumah tangga tahunan sebesar 26\%. Kontribusi tersebut lebih rendah jika dibandingkan dengan hasil penelitian Suwardi et al. (2020a) di kabupaten Aceh Selatan. Dari semua rumah tangga yang menjual buah-buahan, 35\% diantaranya memperoleh penghasilan tahunan kurang dari Rp. 15.000.000, 46\% berpenghasilan antara Rp 15.000.000 - Rp. 20.000.000, dan selebihnya memperoleh penghasilan lebih dari Rp. 20.000.000. Beberapa spesies yang belum dibudidayakan secara intensif, seperti $\mathrm{M}$. foetida dan M. Odorata juga memiliki nilai ekonomis dan disukai oleh masyarakat karena rasanya yang manis dan berbau harum. Hal ini 
sesuai dengan hasil penelitian Suwardi et al. (2019a) bahwa tumbuhan buah-buahan liar juga memiliki rasa dan aroma yang hampir sama dengan tumbuhan buah budidaya. Tumbuhan buah diketahui memiliki nutrisi yang penting bagi kesehatan manusia (Navia et al., 2017 ; Suwardi et al., 2018 ; Suwardi et al., 2019b ; Navia et al., 2019 ; Suwardi et al., 2020b ).

\section{Persepsi Petani terhadap Agroforestri dengan Buah Buah Lokal}

Persepsi petani terhadap tumbuhan buah potensial untuk dikembangkan di kecamatan Birem Bayeun menunjukkan perbedaan (Tabel 3).

Tabel 3. Sepuluh Jenis Tumbuhan Buah-Buahan Lokal Potensial berdasarkan Informasi Responden

\begin{tabular}{|c|c|c|c|c|c|c|c|}
\hline \multirow[b]{2}{*}{ Nama Spesies } & \multicolumn{5}{|c|}{ Kriteria } & \multirow[b]{2}{*}{ Jumlah } & \multirow[b]{2}{*}{ Ranking } \\
\hline & Rasa & $\begin{array}{c}\text { Nilai } \\
\text { Ekonomis }\end{array}$ & Ketersediaan & $\begin{array}{c}\text { Kesesuaian } \\
\text { Lahan }\end{array}$ & $\begin{array}{c}\text { Teknik } \\
\text { Budidaya }\end{array}$ & & \\
\hline Citrus sinensis & 4,2 & 4,4 & 4,1 & 4,5 & 4,1 & 21,3 & 1 \\
\hline Musa acuminata & 4,1 & 4,2 & 3,8 & 3,8 & 3,9 & 19,8 & 2 \\
\hline Carica papaya & 3,9 & 4,0 & 3,7 & 3,9 & 3,8 & 19,3 & 3 \\
\hline Ananas comosus & 4,0 & 4,2 & 3,8 & 3,8 & 3,1 & 18,9 & 4 \\
\hline Cocos nucifera & 4,0 & 3,3 & 3,7 & 4,1 & 3,6 & 18,7 & 5 \\
\hline Durio zibethinus & 4,1 & 4,0 & 3,6 & 3,5 & 3,3 & 18,5 & 6 \\
\hline Artocarpus heterophyllus & 3,5 & 3,9 & 4,0 & 3,7 & 3,1 & 18,2 & 7 \\
\hline Psidium guajava & 3,7 & 4,0 & 3,6 & 3,4 & 3,3 & 18,0 & 8 \\
\hline Manilkara zapota & 2,6 & 3,8 & 3,2 & 3,2 & 2,9 & 15,7 & 9 \\
\hline Theobroma cacao & 3,3 & 3,2 & 2,9 & 3,1 & 2,8 & 15,3 & 10 \\
\hline
\end{tabular}

Jeruk manis (C. sinensis) meruapakan tumbuhan buah yang paling disukai oleh petani untuk dikembangkan dalam system agroforestri. Saat ini, $C$. sinensis telah dibudidayakan pada lahan perkebunan masyarakat di desa Jambur Labu dan Bukit Seuleumak. Meskipun demikian, pisang $(M$. paradisiaca) dan papaya ( $C$. papaya) juga memiliki potensi untuk dikembangkan. Jenisjenis tumbuhan buah tersebut berpotensi untuk dikembangkan karena dianggap mudah dalam pemeliharaannya dan mudah dalam pemasaran.

Konsep budidaya tumbuhan buah dalam sistem agroforestri dapat dilakukan dengan mempelajari metode yang telah diterapkan di berbagai daerah, misalnya di Rwanda. Petani di Rwanda telah mengkombinasikan tumbuhan buah seperti Markhamia lutea (Benth.) K.Schum
(Bignoniaceae), Ficus spp. (Moraceae), Vernonia amygdalina Delile (Compositae), Iboza riparia (Hochst.) N.E.Br. (Lamiaceae), Erythrina abyssinica DC. (Fabaceae), Persea americana Mill. (Lauraceae) dan Citrus sinensis (L.) Osbeck (Rutaceae) di lahan pertanian mereka untuk tujuan ekonomi, sosial, ekologis, dan budaya (Habiyambere, 1999; Bucagu et al., 2013; Iiyama et al., 2018). Mereka juga menanam Sesbania sesban (L.) Merr. (Leguminosae), Leucaena leucocephala (Lam.) De Wit. (Leguminosae), dan Calliandra calothyrsus Meisn. (Leguminosae) untuk meningkatkan kesuburan tanah dan penyediaan pakan ternak (Niang et al. 1998; Bucagu et al., 2013). Pengembangan agroforestri dengan mengkombinasikan tumbuhan buah dengan berbagai jenis tanaman pertanian di lahan pertanian dianggap memiliki efek positif terhadap sifat fisik dan kimia tanah. Konsep 
ini dapat melindungi lahan pertanian dari erosi tanah, meningkatkan iklim mikro dan memenuhi kebutuhan petani terhadap kayu bakar, bahan konstriksi, pakan ternak, dan bahan pagar (Fadl \& Gebauer, 2004) dan juga dapat memenuhi kepentingan sosial, ekonomi, dan ekologi masyarakat (Prasmatiwi et al., 2010).

\section{KESIMPULAN}

Sebanyak 30 jenis tumbuhan yang terdiri dari 20 famili dan 29 genus ditemukan pada lokasi penelitian. Famili yang paling banyak adalah Lauraceae dan Rosaceae yang paling banyak dan diwakili oleh masingmasing lima spesies jumlah yang dijual ada 29 buah. Berapa kontribusi penjualan buah terhadap pendapatan rumah tangga petani Kontribusi tumbuhan buah terhadap total pendapatan rumah tangga tahunan sebesar26\%. Kontribusi tersebut lebih rendah jika dibandingkan dengan hasil penelitian Suwardi et al. (2020a) di kabupaten Aceh Selatan.Dari semua rumah tangga yang menjual buah-buahan, 35\% diantaranya memperoleh penghasilan tahunan kurang dari Rp. 15.000.000, 46\% berpenghasilan antara Rp15.000.000 - Rp. 20.000.000, danselebihnya memperoleh penghasilanlebih dari Rp. 20.000.000. Beberapa spesies yang belum dibudidayakan secara intensif, seperti M. foetida dan M. Odorata juga memiliki nilai ekonomis dan disukai oleh masyarakat karena rasanya yang manis dan berbau harum. Jenis apa yang paling potensial untuk dikembangkan itu adalah citrus sinensis, di antara 10 jenis yang berptnsial adalah Citrus sinensis, Musa acuminate, Carica papaya, Carica papaya, Ananas comosus, Cocos nucifera, Durio zibethinus, Artocarpus heterophyllus, Psidium guajava,, Manilkara zapota, Theobroma cacao.

\section{DAFTAR PUSTAKA}

Amin, M., Rachman, I. \& Ramlah, S. Jenis Agroforestri Dan Orientasi Pemanfaatan Lahan Di Desa Simoro Kecamatan Gumbasa Kabupaten Sigi. No.1. Vol.4 Hal.97-104. Sulawesi Tengah.

Bucagu, C., Vanlauwe, B., Van Wijk, M.T. \& Giller, K.E. (2013). Assessing farmers' interest in agroforestry in two contrasting agroecological zones of Rwanda. Agroforest Systems, 87, 141158.

Dwiratna, N.P.S., Widyasanti, A. \& Rahman, D.M. 2016. Pemanfaatan Lahan Pekarangan Dengan Menerapkan Konsep Kawasan Rumah Pangan Lestari. Jurnal Aplikasi Ipteks Untuk Masyrakat. No.1 Vol.5 Hal.19-22. Jatinangor

Fadl, K.E.M. \& Gebauer, J. (2004). Crop performance and yield of Groundnut, Sesame and Roselle in agroforestry cropping system with Acacia senegal in North Kordofan (Sudan). Journal of Agriculture and Rural Development in the Tropics and Subtropics, 105 (2), $149-154$

Feriatin. 2017. Keanekaragaman Tanaman Pekarangan Dan Pemanfaatannya Untuk Mendukung Ketahanan Pangan Kecamatan Wakorumbo Selatan. Jurnal Ilmu Pertanian Indonesia. Vol.22 Hal.99-107. Sulawesi Tenggara

Habiyambere, T. (1999). Etude pour l'élaboration d'un plan d'action stratégique pour la conservation et la gestion de la biodiversité des écosystèmes: Cas du Rwanda. Direction des Forêts, Kigali.

Kurniawan, H. \& Eko, P. 2018 Potensi Pengembangan Tanaman Asli Setempat Dalam System Agroforestri Studi Kasus Di Desa T'eba Kabupaten Timor Tengah 
Utara Nusa Tenggara Timur. Jurnal FALOAK. No.2 Vol.2 Hal.71-88. Kupang.

Kristanti, T. \& Sitepu, T. 2013. Sistem Pakar Hama Dan Penyakit Pada Tanaman Jeruk Manis Di Kabupaten Karo. Seminar Nasional Sistem Informasi Indonesia. Sumatera Utara.

Iiyama, B.M.M., Mukuralinda, A., Ndayambaje, J.D., Ndoli, A., Mowo, J.G., Garrity, D., Ling, S. \& Ruganzu, V. (2018). Tree-Based Ecosystem Approaches (TBEAs) as MultiFunctional Land Management Strategies-Evidence from Rwanda. Sustainability, 10, 1360

Niang, A., Styger, E., Gahamanyi, A., Hoekstra, D., \& Coe, R. (1998). Fodderquality improvement through contourplanting of legume-shrub/grass mixtures in croplands of Rwanda Highlands. Agrofor. Syst., 39, 263-274

Prasmatiwi, F.E., Irham, Suryantini, A. \& Jamhari. (2010). Determinants of the Adoption of Shade Systems and Their Effects on Coffee Farming Productivity and Income in West Lampung Regency. Agriekstensia, 9 (2),160-172

Suwardi, A.B., Indriaty \& Navia, Z.I. (2018). Nutritional evaluation of some wild edible tuberous plants as an alternative Foods. Innovare Journal of Food Sci, 6(2), 9-12

Suwardi, A. B., Navia, Z. I., Harmawan, T., Syamsuardi, \& Mukhtar, E. (2019a). Sensory Evaluation of Mangoes Grown in Aceh Tamiang District, Aceh, Indonesia. Advances in Ecological and Environmental Research, 4(3), 79-85.

Suwardi, A.B., Navia, Z.I., Harmawan, T., Syamsuardi, \& Mukhtar, E. (2019b). The diversity of wild edible fruit plants and traditional knowledge in West Aceh region, Indonesia. Journal of Medicinal Plants Studies, 7(4), 285-290

Suwardi, A.B., Navia, Z.I., Harmawan, T., Syamsuardi \& Mukhtar, E. (2020a). Ethnobotany and conservation of indigenous edible fruit plants in South Aceh, Indonesia. BIODIVERSITAS, 21 (5), 1850-1860

Suwardi, A.B., Navia, Z.I., Harmawan, T., Syamsuardi \& Mukhtar, E. (2020b). Ethnobotany, nutritional composition and sensory evaluation of Garcinia from Aceh, Indonesia. Materials Science and Engineering, 725(1), 012064 